\title{
Analysis of Early and Late Cases of Idiopathic Abruptio Placenta in Preterm Patients
}

\author{
Işıl Uzun Çilingir (D), Füsun Varol, Havva Sütçü, Cihan Inan, Cem Yener, Cenk Sayın \\ Department of Perinatology, Trakya University School of Medicine, Edirne, Turkey
}

Cite this article as: Uzun Çilingir I, Varol F, Sütçü H, Inan C, Yener C, Sayın C. Analysis of Early and Late Cases of Idiopathic Abruptio Placenta in Preterm Patients. JAREM 2019; 9(Supplement 1): S19-22.

\begin{abstract}
Objective: To evaluate the cases of idiopathic abruptio placenta in early and late preterm period.

Methods: Normotansive singleton pregnancies with the diagnosis of abruptio placenta between 23 and 37 weeks of pregnancy were included in the study. The patients with a risk factor for abruptio plaicenta (preeclampsia, travma, heavy smoking, polyhydoamnios etc) were excluded from the study. The patients were divided into two groups according to the gestational weeks at delivery. Group I was consisted of the pregnant patiens between 23 and 32 weeks of gestation and group II was consisted of pregnant patients between 32 and 37 weeks of gestation.

Results: Mean maternal age of the pregnant patients was 28.3 years. The demographic characteristics were smilar in the groups. The most common complaint at the admission was bleeding in group I $(13 / 17,76.4 \%)$, whereas pain $(5 / 11,45.4 \%)$ in group II. There were statistically significant difference in breech and transvers position of the fetuses between the early cases and late cases of abruptio placenta ( $p<0.05)$.

Conclusion: Abruptio placenta may occur even in the patients without any risk factors. It should be borne in mind that abruptio placenta may have may different clinical presentations. It has different clinical symptoms and prognosis in early and late preterm period.

Keywords: Abruptio placenta, preterm, idiopathic
\end{abstract}

\section{INTRODUCTION}

Abruptio placenta is defined as complete or partial separation of placenta before delivery. It occurs in around 1\% of all pregnancies and has many risk both for fetus and mother (1). Abruptio placenta may cause massive hemorrhage, disseminated intravascular coagulopathy (DIC) in pregnant women, and may cause preterm birth, neonatal morbidity and perinatal death (2).

The rate of placental abruption varies by gestational age at delivery with the rate being 10-fold higher at very preterm gestations and sharply declining as pregnancy progresses toward term $(3,4)$.

Some form of hypertension is the most frequent condition associated with placental abruption. This includes gestational hypertension, preeclampsia, chronic hypertenison and superimposed preeclampsia (5). However history of abruptio placenta in the previous pregnancy has the highest relative risk for abruptio placenta. A recently published study concluded that abruptio placenta may be associated with DNA variants encoding for genes involved in mitochondrial biogenesis and oxidative phosphorylation pathways (6).
In this study we have aimed to evaluate the early onset and late onset cases of abruptio placenta in normotansive preterm pregnant patients without a known cause for abruptio placenta.

\section{METHODS}

After ethical approval, the study sample was drawn from 5102 pregnancies in high risk pregnancy clinic of Trakya University School of Medicine, between January 2012 and June 2018. This was a retrospective cohort study so the patient's consent was not undertaken. Normotansive singleton pregnancies with the diagnosis of abruptio placenta between 23 and 37 weeks of pregnancy were included in the study. Gestational hypertension, preeclampsia, chronic hypertension, superimposed preeclampsia, multiple pregnancy, abdominal travma, history of abruptio placenta, history of recurrent pregnancy loss, trombophlia, gestation $>37$ week, heavy smoking, macrosomia, polyhydroamios, uterine leiyomyoma were the exclusion criterias.

The patients were divided into two groups according to the gestational weeks at delivery.

ORCID ID of the author: I.U.Ç. 0000-0003-3196-770X. 
Group I was consisted of the pregnant patiens between 23 and 32 weeks of gestation and group II was consisted of pregnant patients between 32 and 37 weeks of gestation.

Abruptio placenta was defined as complete and partial seperation of placenta before delivery (Figure 1).

The diagnosis of placental abruption were made by clinical signs and symptoms (Bleeding, tense and tender abdomen) and confirmed by local examination of placenta for seperation and presence of retroplacental blood clots or hematoma formation.

The clinical findings at the admission, Intra uterine growth retardation (IUGR), gravidity, parity, sonographic findings, medical history, obstetric history,apgar score at 1 and 5 minutes, perinatal mortality, weigth of the newborn, postpartum hemorrhage and disseminated intravascular coagulation (DIC) were analysed and compared between the groups.

\section{Statistical Analysis}

Statistical analyses were performed using the Number Cruncher Statistical System (NCSS 2007) (Kaysville, Utah, USA). Data were

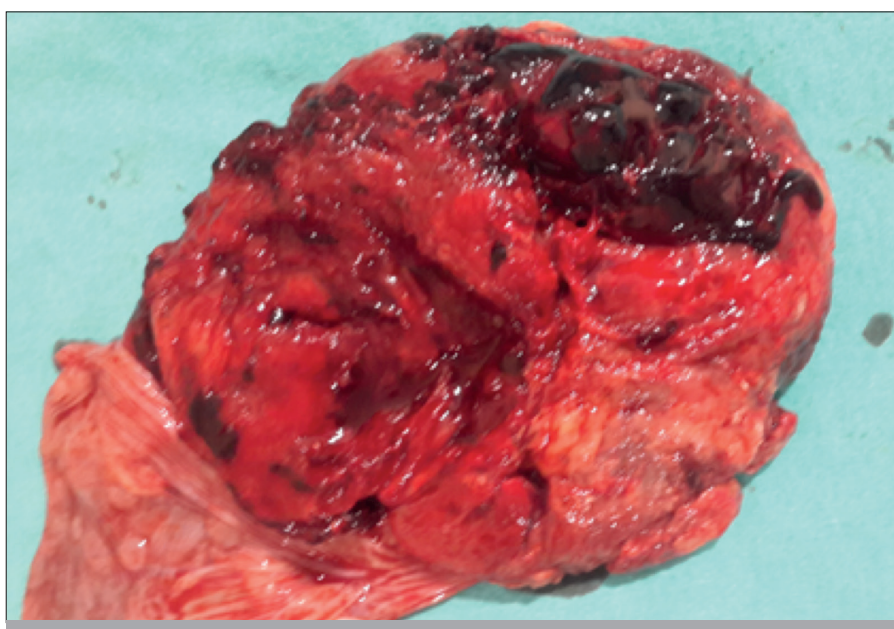

Figure 1. Abruptio placenta

Table 1. The pregnancy results of the groups

\begin{tabular}{|l|c|c|c|}
\hline & $\begin{array}{c}\text { Group I } \\
(\mathbf{n}: 17)\end{array}$ & $\begin{array}{c}\text { Group II } \\
\text { (n:11) }\end{array}$ & $\mathbf{p}$ \\
\hline PPROM & $3 / 17$ & $0 / 11$ & NS \\
\hline IUGR & $2 / 17$ & $2 / 11$ & NS \\
\hline IUD & $0 / 17$ & $2 / 11$ & NS \\
\hline $\begin{array}{l}\text { Malpresentation } \\
\text { (transverse,breech }\end{array}$ & $10 / 17$ & $1 / 11$ & p $<0.05$ \\
\hline Apgar scores 1 minute $<7$ & $7 / 17$ & $6 / 9$ & NS \\
\hline Apgar scores 1 minute<7 & $8 / 17$ & $3 / 9$ & NS \\
\hline $\begin{array}{l}\text { NS: non significant; PPROM: preterm premature rupture of membranes; } \\
\text { IUGR: intrauterine growth retardation; IUD: intrauterine demise }\end{array}$ &
\end{tabular}

analyzed using descriptive statistical procedures (mean, median, frequency, standard deviation, minimum, and maximum). Student's t test was done to compare normally distributed variables, while Mann-Whitney $U$ test was used to compare variables, which were not normally distributed. Fisher's exact test and Yates' continuity correction test were preferred to compare the data. $p<0.05$ was considered to be statistically significant.

\section{RESULTS}

During the study period 28 patients were fullfilled the inclusion criteria. 17 patients were between 23 and 32 weeks of gestation (group I) and 11 patients were bigger than 32 weeks of gestation (Group II).

Mean maternal age of the pregnant patients was 28.3 years. The demographic characteristics were smilar in the groups.

The most common complaint at the admission was bleeding in group I $(13 / 17,76.4 \%)$, whereas pain $(5 / 11,45.4 \%)$ in group II. Preterm premature rupture of membranes (PPROM) was together with bleeding in three patients $(3 / 17,1.6 \%)$ in group I. None of the patients had PPROM after 32 weeks of gestation (Group II). Intrauterine fetal demise (IUD) was detected at the admission in two patients in group II. IUD was not detected in group I. DIC was developed in the patients with IUD which necessiated long term hospitalization and massive transfusion of the blood products. IUGR was found in two patients in group I $(2 / 17,11.7 \%)$ and two patients in group II $(2 / 11,18 \%)$ (Table 1).

The medical and obstetric history, gravidity, parity were not different in the groups.

Malpresentation was detetected in 10 patients (58\%) in group I and only in one patient $(0.9 \%)$ in group II. There was statistically significant difference in breech and transvers position of the fetuses between the early cases and late cases of abruptio placenta $(p<0.05)$ (Table 1).

The mean weigth of all newborns was $1637 \mathrm{gr}$ (470-2790). Apgar score at 1 minute was below 7 in 11 patients (64.7\%) and Apgar score at 5 minute was below 7 in 8 patients (47\%) in group I. After excluding the two patients with IUD, 6 patients (66\%) had Apgar scores lower than 7 at 1 minute and 3 patients (33.3\%) had Apgar scores lower than 7 at 5 minute. The apgar scores at 1 and 5 minute were smilar between the groups.

\section{DISCUSSION}

Prior abruption, increased age and parity, preeclampsia, chronic hypertension, choriamnionitis, multiple gestation, low birthweigth, hydramnios, cigarette smoking, tombophilias, cocaine use, uterine leiyomyoma has been defined as the risk factor for abruptio placenta in many studies $(7,8)$. Some rare causes of abruptio placenta as acute pancreatitis has also been reported as case reports (9).

In this study we have carefuly screened the study sample for the risk factors. The patients without any risk factor were in- 
cluded in the study to evaluate the idiopathic abruptio placenta in early and late preterm pregnancies. We have also classified the patients according to the gestational weeks; because we beleive that the patients in early preterm (23-32 weeks) and late preterm period (32-27 weeks) should evaluate in seperate sections.

The pregnant patients who have admitted with bleeding in early preterm period with breech and transverse position seems to be strong candidates for idiopathic abruptio placenta.

Malpresentation was significantly increased in early idiopthic abruptio plasenta. The association between malpresantation and abruptio placenta has been reported before (7). The ratio of non vertex position has been reported as $19.1 \%$ in the patients with abruptio placenta and $5.3 \%$ in the patients without abruptio placenta. But in that study, all cases of abruptio placenta up to 42 weeks of pregnancy were included. The ratio of non vertex position was much more higher (58\%) in our early preterm patients. We can think that the association between the malpresantion and abruptio placenta seems to be stronger in early preterm period ( $<32$ weeks of getatioun). However the cause of increased incidence of abruptio placenta in non vertex position is stil an enigma.

The most common complaint at the admission was bleeding in early preterm period (23-32 weeks of gestation9 (13/17, $76.4 \%)$, whereas pain $(5 / 11,45.4 \%)$ in group II (>32 weeks of gestation).

In a study cases of abruptio placenta were classifed according to the primary symptoms as bleeding and pain groups. They have found that primary symptoms of placental abruption were associated with preterm birth and PE and abdominal pain as a primary symptom predicts poorer pregnancy outcomes in both mothers and neonates (10). Conflict results have been reported about the primary symptoms and the maternal and perinatal outcomes $(11,12)$.

But in these studies all of the cases of abruptio placenta were included. Maternal and neonatal results would also be affected by the presence of preeclampsia and other associated conditions. In our study we have excluded the patients with associated conditions and we have found no significant difference in Apgar scores at 1 and 5 minute between the groups. Gestational week is the main factor of the neonatal prognosis; so it is hard to make a subjective analysis for neonatal results of the cases.

Intra uterine demise was found in two cases in our sample. They have admitted with pain at 34 and 37 weeks of gestation. Ultrasound revealed IUD. Both of the cases were developed DIC after delivery. IUD was not detected in the cases at early preterm period.

\section{CONCLUSION}

Abruptio placenta may occur even in the patients without any risk factors. It should be borne in mind that abruptio placenta may have may different clinical presentations. It has different clinical symptoms and prognosis in early and late preterm period.

Ethics Committee Approval: Ethics committee approval was received for this study from the Ethics Committee of Trakya University School of Medicine.

Informed Consent: Informed consent was not taken from patients due to the retrospective nature of the study.

Peer-review: Externally peer-reviewed.

Author Contributions: Concept - I.U.Ç., C.S.; Design - I.U.Ç., F.V.; Supervision - I.U.Ç., F.V., C.I., C.S.; Resources - I.U.Ç., C.Y., H.S.; Materials - C.Y., H.S. ; Data Collection and/or Processing - I.U.Ç., H.S.; Analysis and/or Interpretation - I.U., H.S., F.V.; Literature Search - C.I., H.S.; Writing Manuscript - I.U., F.V.; Critical Review - F.V., C.S.

Conflict of Interest: The authors have no conflict of interest to declare.

Financial Disclosure: The authors declared that this study has received no financial support.

\section{REFERENCES}

1. Ananth CV, Savitz DA, Williams MA. Placental abruption and its association with hypertension and prolonged rupture of membranes: a methodologic review and meta-analysis. Obstet Gynecol 1996; 88: 309-18. [CrossRef]

2. Oyelese Y, Ananth CV. Placental abruption. Obstet Gynecol 2006; 108: 1005-16. [CrossRef]

3. Sheiner E, Shoham-Vardi I, Hadar A, Hallak M, Hackmon R, Mazor M. Incidence, obstetric risk factors and pregnancy outcome of preterm placental abruption: a retrospective analysis. J Matern Fetal Neonatal Med 2002; 11: 34-9. [CrossRef]

4. Sheiner E, Shoham-Vardi I, Hallak M, Hadar A, Gortzak- Uzan L, Katz $\mathrm{M}$, et al. Placental abruption in term pregnancies: clinical significance and obstetric risk factors. J Matern Fetal Neonatal Med 2003;13: 45-9. [CrossRef]

5. Pritchard JA, Cunningham FG, Pritchard SA, Mason RA. On reducing the frequency of severe abruptio placenta. Am J Obstet Gynecol 1991; 165: 1345-51. [CrossRef]

6. Workalemahu T, Enquobahrie DA, Bizu Gelaye B, Thornton TA, Tekola-Ayele F, Sanchez SE, et al. Abruptio placentae risk and genetic variations in mitochondrial biogenesis and oxidative phosphorylation: replication of a candidate gene association study. Am J Obstet Gynecol 2018; 219: 617. [CrossRef]

7. Pariente G, Wiznitzer A, Sergienko R, Mazor M, Holcberg G, Sheiner E. Placental abruption: critical analysis of risk factors and perinatal outcomes. J Matern Fetal Neonatal Med 2011; 24: 698702. [CrossRef]

8. Nath CA, Ananth CV, DeMarco C, Vintzileos AM; New Jersey-Placental Abruption Study Investigators. Low birth weigth in relation to placental abruption and maternal thrombophilia status. Am J Obstet Gynecol 2008; 198: 293. [CrossRef]

9. Yalcin Bahat P, Turan G, Aslan Cetin B. Abruptio Placentae Caused by Hypertriglyceridemia-Induced Acute Pancreatitis during Pregnancy: Case Report and Literature Review. Case Report Obstet Gynecol 2018; 2018: doi: 10.1155/2018/3869695. [CrossRef]

10. Mei Y, Lin Y. Clinical significance of primary symptoms in women with placental abruption. J Matern Fetal Neonatal Med 2018; 31: 2446-9. [CrossRef] 
11. Chang YL, Chang SD, Cheng PJ. Perinatal outcome in patients with placental abruption with and without antepartum hemorrhage. Int J Gynecol Obstet 2001; 75: 193-4. [CrossRef]
12. Kasai M, Aoki S, Ogawa M, Kurasawa K, Takahashi T, Hirahara F. Prediction of perinatal outcomes based on primary symptoms in women with placental abruption. J Obstet Gynaecol Res 2015; 41: 850-6. [CrossRef] 